\title{
Transarterial chemoembolization combined with Jie-du granule preparation improves the survival outcomes of patients with unresectable hepatocellular carcinoma
}

\author{
Hetong Zhao ${ }^{1, *}$, Xiaofeng Zhai ${ }^{1,}$, , Zhe Chen ${ }^{1}$, Xuying Wan ${ }^{2}$, Lanyu Chen ${ }^{1}$, Feng \\ Shen $^{3, *}$ and Changquan Ling ${ }^{1, *}$ \\ ${ }^{1}$ Department of Traditional Chinese Medicine, The Changhai Hospital, Second Military Medical University, Shanghai, China \\ ${ }^{2}$ Department of Combined Traditional Chinese and Western Medicine, The Eastern Hepatobiliary Surgery Hospital, Second \\ Military Medical University, Shanghai, China \\ ${ }^{3}$ Department of Hepatic Surgery, The Eastern Hepatobiliary Surgery Hospital, Second Military Medical University, Shanghai, \\ China \\ "These authors contributed equally to this work
}

Correspondence to: Changquan Ling, email: changquanling@smmu.edu.cn Feng Shen, email: shenfengehbh@sina.com

Keywords: hepatocellular carcinoma, Jie-du granule, transarterial chemoembolization, retrospective cohort study

Received: December 22, $2016 \quad$ Accepted: March 22, $2017 \quad$ Published: April 03, 2017

Copyright: Zhao et al. This is an open-access article distributed under the terms of the Creative Commons Attribution License 3.0 (CC BY 3.0 ), which permits unrestricted use, distribution, and reproduction in any medium, provided the original author and source are credited.

\section{ABSTRACT}

The aim of the present study was to compare the effectiveness of transarterial chemoembolization (TACE), TACE combined with Jie-du granules (JD), and TACE combined with sorafenib (SOR) for treating patients with unresectable hepatocellular carcinoma (HCC). For this purpose, we conducted a retrospective analysis of data from 266 consecutive patients with unresectable HCC who underwent TACE treatment at the Shanghai Hospital and Eastern Hepatic Surgery Hospital between Jan 2009 and Dec 2010. We prospectively analyzed patient survival and progression times as well as independent predictors, within a follow-up period of $\mathbf{8 6}$ months. Patients were divided into TACE-JD $(n=75)$, TACE-SOR $(n=124)$ and TACE $(n=67)$ groups. Median overall survival (OS) times being: TACE-JD, 21.43 months; TACE-SOR, 23.23 months; TACE, 13.97 months (TACE-SOR vs TACE, $P<0.001$; TACE-SOR vs TACE-JD, $P=0.852$; TACE-JD vs TACE, $P<0.001$ ). The median times to progression (TTP) were as follows: TACE-JD, 8.67 months; TACE-SOR, 5.37 months; TACE, 4.57 months (TACE-SOR vs TACE, $P=0.479$; TACE-SOR vs TACE-JD, $P<0.001$; TACE-JD vs TACE, $P<0.001)$. Independent predictors of OS were treatment allocation, Child-Pugh class large tumor, albumin and extrahepatic metastasis. These findings show that patients with unresectable HCC who were administered TACE-JD survived significantly longer compared with those administered TACE or TACE-SOR.

\section{INTRODUCTION}

Hepatocellular carcinoma (HCC) is the sixth most common cancer and second leading cause of cancerrelated death worldwide [1-2]. Liver resection and transplantation may offer curative treatment for patients with HCC, and percutaneous radiofrequency ablation may have a potentially curative effect, but most patients are unable to undergo these treatments because of advanced disease upon diagnosis. Transarterial chemoembolization (TACE) is an effective, commonly used treatment for patients whose conditions are unsuitable for surgical or ablative procedures [3-4]. TACE combined with other treatments may improve the outcomes of patients with unresectable HCC. For example, bevacizumab [5], sorafenib [6], and arsenic trioxide [7] combined with TACE can prolong the survival of patients with HCC. Further, a meta-analysis found that TACE plus sorafenib (TACE-SOR) administered to patients with intermediate or advanced HCC improved overall survival (OS), time to progression (TTP), and the overall response rate [8-12]. However, a phase III randomized controlled trial found that that TACE-SOR did not clinically improve TTP compared with TACE in patients with intermediate 
stage multinodular HCC and that the time to unTACEable progression (TTUP) was lower for patients administered sorafenib compared with those given placebo [8].

The Chinese herbal formula Jie-du granule preparation (JD), which is widely used for treating HCC, comprises anticancer and detoxifying endotoxic Chinese herbal medicines prepared according to the theory of traditional Chinese herbal medicine. For example, a few studies have demonstrated that TACE combined with JD granules may prolong the survival of patients with unresectable HCC [13-16]. In the present study, we compared the efficacy of TACE, TACE plus JD (TACE-JD), and TACE-SOR for treating patients with unresectable HCC.

\section{RESULTS}

\section{Patient characteristics}

The baseline characteristics of the 266 patients among the three groups were not significantly different (Table 1). We then compared TTP and OS among the TACE-JD, TACE-SOR, and TACE groups to identify associated factors and establish the efficacy of TACE-JD compared with TACE-SOR and TACE alone.

\section{OS and TTP}

During the median follow-up of 18.76 months (range, 1-88 months), 210 patients (78.9\%) died from HCC. The TACE-JD and TACE-SOR groups experienced significantly longer OS (21.43 months and 23.23 months, respectively) compared with that of the TACE group (13.97 months; $P<0.001$ ) but there was no significant difference between the TACE-SOR and TACE-JD groups $(P=0.852)$ (Figure 1A). Additionally, the TACE-JD

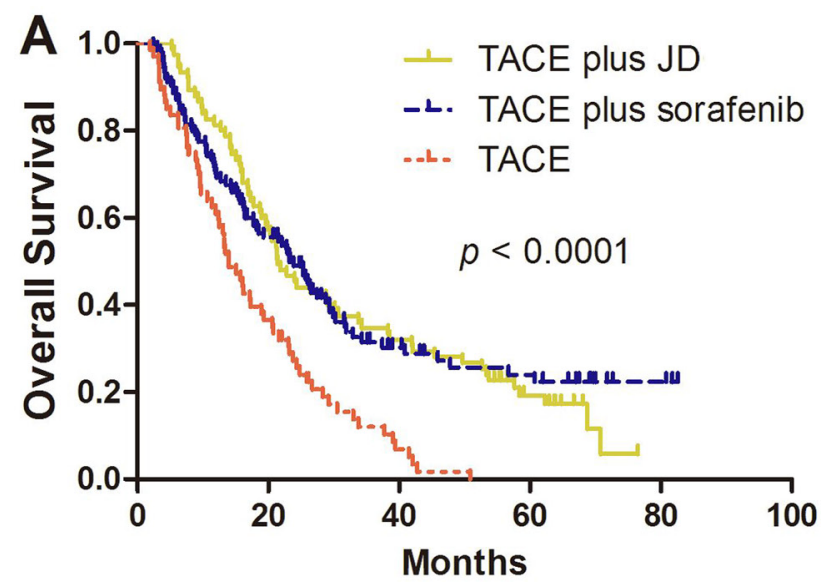

group experienced significantly longer TTP (8.67 months) compared with patients receiving TACE alone (4.57 months; $P<0.001$ ) or TACE-SOR (5.37 months; $P<0.001)$. Furthermore, there was no significant difference between TACE-SOR and TACE only groups $(P=0.479)$ (Figure 1B).

\section{Independent prognostic factors associated with OS and TTP}

Univariate analysis revealed that improved OS was significantly associated with treatment allocation, ECOG performance, large tumor size, extrahepatic metastasis, and aspartate transaminase (AST) (Table 2). Multivariate analysis identified treatment allocation, Child-Pugh class, large tumor size, albumin, and extrahepatic metastasis as independent predictors of OS (Table 3). Univariate analysis revealed that improved TTP was significantly associated with treatment allocation, age, portal vein tumor thrombosis, extrahepatic metastasis, and AST (Table 2). Multivariate analysis identified treatment allocation, AST, albumin, and extrahepatic metastasis as independent predictors of TTP (Table 4).

\section{Comparison of cost-effectiveness}

Although there were no significant differences in hospitalization costs between the three treatment groups, admission costs of the TACE-JD group were significantly lower compared with those of the TACE-SOR group $(P<0.001)$ (Table 5).

\section{DISCUSSION}

Herein we compared OS and TTP of patients with unresectable HCC who were treated with TACE alone,

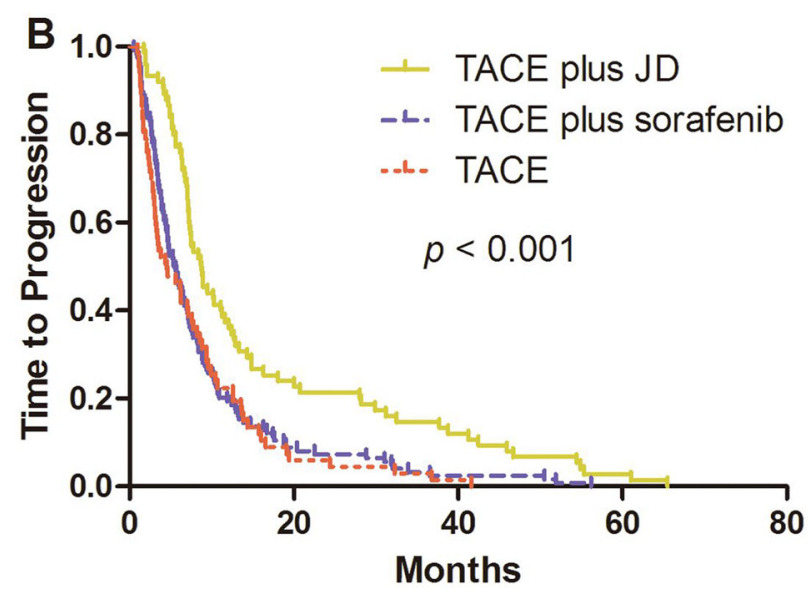

Figure 1: Kaplan-Meier curves of (A) OS and (B) TTP of patients with unresectable HCC who were administered TACE, TACE-SOR, or TACE-JD. (A) OS was significantly improved in the TACE-JD and TACE-SOR groups compared with TACE alone. TACE-JD vs TACE, $P<0.001$; TACE-SOR vs TACE, $P<0.001$; TACE-JD vs TACE-SOR, $P=0.852$. (B) TTP was significantly improved by administration of TACE-JD compared with both TACE-SOR and TACE alone. TACE-JD vs TACE, $P<0.001$; TACE-JD vs TACE-SOR, $P<0.001$; TACE-SOR vs TACE, $P=0.476$. 
Table 1: Patients' baseline demographics, disease characteristics, and treatments

\begin{tabular}{|c|c|c|c|c|}
\hline Treatment & TACE plus JD $(N=75)$ & $\begin{array}{l}\text { TACE plus Sorafenib } \\
\qquad(N=124)\end{array}$ & TACE $(N=67)$ & $p$ value \\
\hline Age (yr) & $55.2 \pm 11.6$ & $50.7 \pm 12.2$ & $51.7 \pm 11.1$ & 0.053 \\
\hline Gender & & & & 0.509 \\
\hline Male & $66(88.0 \%)$ & $108(87.1 \%)$ & $62(92.5 \%)$ & \\
\hline Female & $9(12.0 \%)$ & $16(12.9 \%)$ & $5(7.5 \%)$ & \\
\hline Child-pugh class & & & & 0.645 \\
\hline A & $67(89.3 \%)$ & $107(86.3 \%)$ & $61(91.0 \%)$ & \\
\hline B & $8(10.7 \%)$ & $17(13.7 \%)$ & $6(9.0 \%)$ & \\
\hline ECOG performance status & & & & 0.068 \\
\hline 0 & $44(58.7 \%)$ & $77(62.1 \%)$ & $43(64.2 \%)$ & \\
\hline 1 & $24(32.0 \%)$ & $36(29.0 \%)$ & $24(35.8 \%)$ & \\
\hline 2 & $7(9.3 \%)$ & $11(8.9 \%)$ & $0(0.0 \%)$ & \\
\hline Number of tumors ${ }^{\dagger}$ & & & & $<0.001$ \\
\hline Single & $17(23.3 \%)$ & $61(49.6 \%)$ & $24(35.8 \%)$ & \\
\hline Multiple & $50(68.5 \%)$ & $61(49.6 \%)$ & $43(64.2 \%)$ & \\
\hline Largest tumor size $(\mathrm{cm})$ & & & & 0.003 \\
\hline$<5$ & $33(44.0 \%)$ & $85(68.5 \%)$ & $38(56.7 \%)$ & \\
\hline$\geq 5$ & $42(56.0 \%)$ & $39(31.5 \%)$ & $29(43.3 \%)$ & \\
\hline HBSAG & & & & 0.159 \\
\hline Negative & $19(25.3 \%)$ & $21(16.9 \%)$ & $9(13.4 \%)$ & \\
\hline Positive & $56(74.7 \%)$ & $103(83.1 \%)$ & $58(86.6 \%)$ & \\
\hline Ascites & & & & $<0.001$ \\
\hline Absent & $61(81.3 \%)$ & $119(96.0 \%)$ & $66(98.5 \%)$ & \\
\hline Present & $14(18.7 \%)$ & $5(4.0 \%)$ & $1(1.5 \%)$ & \\
\hline Portal vein thrombosis & & & & 0.031 \\
\hline Absent & $54(73.0 \%)$ & $89(71.8 \%)$ & $59(88.1 \%)$ & \\
\hline Present & $20(27.0 \%)$ & $35(28.2 \%)$ & $8(11.9 \%)$ & \\
\hline Extrahepatic metastasis & & & & 0.727 \\
\hline Absent & $58(78.4 \%)$ & $101(81.5 \%)$ & $56(83.6 \%)$ & \\
\hline Present & $16(21.6 \%)$ & $23(18.5 \%)$ & $11(16.4 \%)$ & \\
\hline Cirrhosis & & & & $<0.001$ \\
\hline Absent & $1(1.3 \%)$ & $68(54.8 \%)$ & $39(58.2 \%)$ & \\
\hline Present & $74(98.7 \%)$ & $56(45.2 \%)$ & $28(41.8 \%)$ & \\
\hline Total bilirubin level (mmol/L) & & & & 0.207 \\
\hline$<18$ & $54(72.0 \%)$ & $74(59.7 \%)$ & $44(65.7 \%)$ & \\
\hline$\geq 18$ & $21(28.0 \%)$ & $50(40.3 \%)$ & $23(34.3 \%)$ & \\
\hline Aspartate transaminase (IU/L) & & & & 0.115 \\
\hline$<64$ & $52(70.3 \%)$ & $90(72.6 \%)$ & $39(58.2 \%)$ & \\
\hline$\geq 64$ & $22(29.7 \%)$ & $34(27.4 \%)$ & $28(41.8 \%)$ & \\
\hline Serum albumin $(g / L)$ & & & & 0.022 \\
\hline$<35$ & $53(70.7 \%)$ & $103(83.1 \%)$ & $59(88.1 \%)$ & \\
\hline$\geq 35$ & $22(29.3 \%)$ & $21(16.9 \%)$ & $8(11.9 \%)$ & \\
\hline
\end{tabular}


a-Fetoprotein level $(\mathrm{ng} / \mathrm{mL})$

0.043
$<500$
$53(76.8 \%)$
$73(58.9 \%)$
$44(65.7 \%)$
$\geq 500$
$16(23.2 \%)$
$51(41.1 \%)$
$23(34.3 \%)$
Prothrombin Time (s)
$<14.3$
$48(68.6 \%)$
$103(83.1 \%)$
$\geq 14.3$
$22(31.4 \%)$
$21(16.9 \%)$
$59(88.1 \%)$

0.01

Abbrevations: TACE, transarterial chemoembolization; JD, Jie-du; ECOG, Eastern Cooperative Oncology Group.

'Eight patients in the TACE plus JD group had missing data.

TACE-SOR or TACE-JD. We found that the combination therapies, TACE-JD and TACE-SOR, were associated with improved OS compared with TACE alone, and TACE-JD was associated with longer TTP compared with both TACE-SOR and TACE alone.

The development and progression of $\mathrm{HCC}$ is complex. First-line treatment for intermediate and advanced HCC in China includes TACE or sorafenib monotherapy [19-21]. The ranges of OS achieved using TACE and TACE-SOR to treat patients with unresectable HCC are 5.1-17 months and 7.5-27 months, respectively [22-23], which is consistent with the results of the present study. The results of the phase II SPACE trial show that TACE-SOR does not improve TTP compared with TACE plus placebo in Western or Eastern patients, $[8,24]$ which is also in agreement with our findings.

Oncologists state that traditional Chinese medicine should be involved in all aspects of HCC treatment [25-26]. For example, a retrospective study showed that TACE combined with a JD granule preparation may prolong survival of patients with unresectable HCC $(9.2$ vs. 5.87 months, $P<0.01)$ [13]. The composition and dose of the JD preparation were equivalent to that of the JD used in the present study. Although OS was similar between the TACE-SOR and TACE-JD groups, secondary and exploratory analyses of TTP suggest that JD may have slowed tumor growth and metastasis. Given the disease complexity characterized by the interplay between HCC and underlying liver disease, TTP serves as a surrogate for OS [27-28]. These results highlight the requirement for prospective studies to define relevant surrogate endpoints for OS,

Prognoses for HCC differ because of the influence of numerous factors [29]. After adjusting for significant factors revealed by univariate analysis, multivariate analysis identified treatment allocation, large tumor size and extrahepatic metastasis as independent predictors of OS and that treatment allocation, Barcelona Clinic Liver Cancer stage and AST were independent predictors of TTP. These results are consistent with the findings of previous studies [29-30]. For example, AST is a significant predictor of survival after diagnosis of HCC in patients with chronic HBV infections, which is in agreement with our findings that AST was an independent predictor of TTP [30].
Our data show that TACE-JD was more economical compared with TACE-SOR. Cost-effectiveness was evaluated roughly by comparing total hospital and admission costs. There were no significant differences between the two combination treatment groups in terms of total hospital costs; however, the cost of admission was lower for the TACE-JD group compared with the TACESOR group, which may be explained by the low price of Chinese herbs compared with the high cost of sorafenib.

The present study has limitations such as the relatively small number of nonrandomized patients, its retrospective nature, and the different treatment periods. However, the safety and effectiveness of the treatments were consistent with those of previous randomized trials. In conclusion, our study suggests that combined treatment with TACE and JD is feasible and beneficial for patients with unresectable HCC. Moreover, TACE-JD was more cost-effective in terms of admission expenses. Further studies are therefore warranted to confirm the efficacy of TACE combined with JD for patients with unresectable HCC.

\section{MATERIALS AND METHODS}

\section{Patients}

In this retrospective study, we collected data for 266 patients with unresectable HCC treated with TACE between January 2009 and December 2010 at the Shanghai Hospital and Eastern Hepatic Surgery Hospital. Patients were followed until April 2016. Patients were allocated into three groups according to the type of initially proposed therapy. Inclusion criteria were as follows: i) HCC diagnosed according to noninvasive criteria consistent with the guidelines of the European Association for the Study of Liver/American Association for the study of Liver Disease or pathological diagnosis; ii) Child-Pugh class A or B liver function; iii) Eastern Cooperative Oncology Group (ECOG) performance score $\leq 2$; iv) $\mathrm{HCC}$ deemed to be unresectable upon review of cross-sectional images of the tumors by two experienced liver surgery specialists at the participating centers; v) Availability of complete medical records and prognostic data. Contrast-enhanced computed tomography (CT) and magnetic resonance imaging (MRI) were used to detect 
Table 2: Univariate analysis of prognostic factors for OS and TTP

\begin{tabular}{|c|c|c|c|c|}
\hline \multirow[t]{2}{*}{ Variable } & & \multirow[t]{2}{*}{$n(\%)$} & OS & \multirow{2}{*}{$\begin{array}{c}\text { TTP } \\
\text { HR(95\% CI }), p \text { value }\end{array}$} \\
\hline & & & HR(95\% CI $), p$ value & \\
\hline \multirow[t]{3}{*}{ Treatment } & TACE & $67(25.2 \%)$ & 1 [Reference] & 1 [Reference] \\
\hline & TACE plus JD & $75(28.2 \%)$ & $0.5(0.3,0.7)<0.001$ & $0.5(0.4,0.7)<0.001$ \\
\hline & $\begin{array}{l}\text { TACE plus } \\
\text { Sorafenib }\end{array}$ & $124(46.6 \%)$ & $0.5(0.3,0.7)<0.001$ & $0.9(0.7,1.2) 0.557$ \\
\hline \multirow[t]{2}{*}{ Age } & $\leq 50$ & $121(45.5 \%)$ & 1 [Reference] & 1 [Reference] \\
\hline & $>50$ & $145(54.5 \%)$ & $0.9(0.7,1.2) 0.518$ & $0.7(0.6,0.9) 0.007$ \\
\hline \multirow[t]{2}{*}{ Gender } & Male & $236(88.7 \%)$ & 1 [Reference] & 1 [Reference] \\
\hline & Female & $30(11.3 \%)$ & $0.9(0.6,1.4) 0.665$ & $0.8(0.6,1.2) 0.358$ \\
\hline \multirow[t]{2}{*}{ Child-pugh class } & A & $235(88.3 \%)$ & 1 [Reference] & 1 [Reference] \\
\hline & $\mathrm{B}$ & $31(11.7 \%)$ & $1.0(0.6,1.5) 0.882$ & $1.3(0.9,1.9) 0.168$ \\
\hline \multirow[t]{3}{*}{ ECOG performance status } & 0 & $164(61.7 \%)$ & 1 [Reference] & 1 [Reference] \\
\hline & 1 & $84(31.6 \%)$ & $1.4(1.1,1.9) 0.022$ & $1.3(1.0,1.6) 0.081$ \\
\hline & 2 & $18(6.8 \%)$ & $1.6(1.0,2.8) 0.075$ & $1.2(0.8,2.0) 0.372$ \\
\hline \multirow[t]{2}{*}{ Number of tumors } & Single & $102(39.8 \%)$ & 1 [Reference] & 1 [Reference] \\
\hline & Multiple & $154(60.2 \%)$ & $1.2(0.9,1.6) 0.268$ & $1.1(0.8,1.4) 0.569$ \\
\hline \multirow[t]{2}{*}{ Largest tumor size $(\mathrm{cm})$} & $<5$ & $156(58.6 \%)$ & 1 [Reference] & 1 [Reference] \\
\hline & $\geq 5$ & $110(41.4 \%)$ & $1.7(1.3,2.2)<0.001$ & $1.2(0.9,1.5) 0.193$ \\
\hline \multirow[t]{2}{*}{$\mathrm{HBsAg}$} & Absent & $49(18.4 \%)$ & 1 [Reference] & 1 [Reference] \\
\hline & Present & $217(81.6 \%)$ & $1.0(0.7,1.4) 0.950$ & $1.0(0.7,1.4) 0.965$ \\
\hline \multirow[t]{2}{*}{ Ascites } & Absent & $246(92.5 \%)$ & 1 [Reference] & 1 [Reference] \\
\hline & Present & $20(7.5 \%)$ & $0.9(0.5,1.5) 0.695$ & $0.9(0.6,1.4) 0.684$ \\
\hline \multirow[t]{2}{*}{ Portal vein thrombus } & Absent & $202(76.2 \%)$ & 1 [Reference] & 1 [Reference] \\
\hline & Present & $63(23.8 \%)$ & $1.3(1.0,1.8) 0.098$ & $1.4(1.0,1.8) 0.029$ \\
\hline \multirow[t]{2}{*}{ Extrahepatic metastasis } & Absent & $215(81.1 \%)$ & 1 [Reference] & 1 [Reference] \\
\hline & Present & $50(18.9 \%)$ & $1.7(1.2,2.4) 0.002$ & $1.8(1.3,2.5)<0.001$ \\
\hline \multirow[t]{2}{*}{ Cirrhosis } & Absent & $108(40.6 \%)$ & 1 [Reference] & 1 [Reference] \\
\hline & Present & $158(59.4 \%)$ & $0.9(0.7,1.2) 0.422$ & $0.7(0.5,0.9) 0.003$ \\
\hline \multirow[t]{2}{*}{$\begin{array}{l}\text { Total bilirubin level } \\
(\mathrm{mmol} / \mathrm{L})\end{array}$} & $<18$ & $172(64.7 \%)$ & 1 [Reference] & 1 [Reference] \\
\hline & $\geq 18$ & $94(35.3 \%)$ & $1.2(0.9,1.6) 0.268$ & $1.2(0.9,1.5) 0.181$ \\
\hline \multirow[t]{2}{*}{$\begin{array}{l}\text { Aspartate transaminase } \\
(\mathrm{IU} / \mathrm{L})\end{array}$} & $<64$ & $181(68.3 \%)$ & 1 [Reference] & 1 [Reference] \\
\hline & $\geq 64$ & $84(31.7 \%)$ & $1.5(1.1,2.0) 0.005$ & $1.5(1.2,2.0) 0.001$ \\
\hline \multirow[t]{2}{*}{ Serum albumin $(g / L)$} & $\geq 35$ & $215(80.8 \%)$ & 1 [Reference] & 1 [Reference] \\
\hline & $<35$ & $51(19.2 \%)$ & $1.1(0.8,1.5) 0.690$ & $1.1(0.8,1.5) 0.509$ \\
\hline \multirow[t]{2}{*}{ a-Fetoprotein level (ng/mL) } & $<400$ & $170(65.4 \%)$ & 1 [Reference] & 1 [Reference] \\
\hline & $\geq 400$ & $90(34.6 \%)$ & $1.1(0.8,1.5) 0.407$ & $1.1(0.9,1.5) 0.300$ \\
\hline \multirow[t]{2}{*}{ Prothrombin Time (s) } & $<14.3$ & $210(80.5 \%)$ & 1 [Reference] & 1 [Reference] \\
\hline & $\geq 14.3$ & $51(19.5 \%)$ & $0.8(0.6,1.2) 0.241$ & $1.0(0.7,1.3) 0.935$ \\
\hline
\end{tabular}

Abbrevations: OS, overall survival; TTP, time to progression; HR, hazard ratio; TACE, transarterial chemoembolization; JD, Jie-du; ECOG, Eastern Cooperative Oncology Group. 
Table 3: Multivariate analysis of prognostic factors for OS

\begin{tabular}{|c|c|c|c|}
\hline \multirow[t]{2}{*}{ Variable } & & \multirow[t]{2}{*}{$n(\%)$} & \multirow{2}{*}{$\frac{\text { OS }}{\text { HR }(95 \% \text { CI }), p \text { value }}$} \\
\hline & & & \\
\hline \multirow[t]{3}{*}{ Treatment } & TACE & $67(25.2 \%)$ & 1 [Reference] \\
\hline & TACE plus JD & $75(28.2 \%)$ & $0.4(0.2,0.6)<0.001$ \\
\hline & $\begin{array}{l}\text { TACE plus } \\
\text { Sorafenib }\end{array}$ & $124(46.6 \%)$ & $0.5(0.4,0.8) 0.002$ \\
\hline \multirow[t]{2}{*}{ Child-pugh class } & A & $235(88.3 \%)$ & 1 [Reference] \\
\hline & B & $31(11.7 \%)$ & $0.5(0.3,1.0) 0.035$ \\
\hline \multirow[t]{2}{*}{ Largest tumor size $(\mathrm{cm})$} & $<5$ & $156(58.6 \%)$ & 1 [Reference] \\
\hline & $\geq 5$ & $110(41.4 \%)$ & $1.8(1.2,2.5) 0.002$ \\
\hline \multirow[t]{2}{*}{ Extrahepatic metastasis } & Absent & $215(81.1 \%)$ & 1 [Reference] \\
\hline & Present & $50(18.9 \%)$ & $1.6(1.1,2.4) 0.026$ \\
\hline \multirow[t]{2}{*}{ Serum albumin $(g / L)$} & $\geq 35$ & $215(80.8 \%)$ & 1 [Reference] \\
\hline & $<35$ & $51(19.2 \%)$ & $1.6(1.1,2.6) 0.029$ \\
\hline
\end{tabular}

Abbrevations: OS, overall survival; HR, hazard ratio; TACE, transarterial chemoembolization; JD, Jie-du.

Table 4: Multivariate analysis of prognostic factors for TTP

\begin{tabular}{|c|c|c|c|}
\hline \multirow[t]{2}{*}{ Variable } & & \multirow[t]{2}{*}{$n(\%)$} & TTP \\
\hline & & & HR(95\% CI $), p$ value \\
\hline \multirow[t]{3}{*}{ Treatment } & TACE & $67(25.2 \%)$ & 1 [Reference] \\
\hline & TACE plus JD & $75(28.2 \%)$ & $0.5(0.4,0.8) 0.005$ \\
\hline & $\begin{array}{l}\text { TACE plus } \\
\text { Sorafenib }\end{array}$ & $124(46.6 \%)$ & $1.0(0.7,1.4) 0.978$ \\
\hline \multirow[t]{2}{*}{ Extrahepatic metastasis } & Absent & $215(81.1 \%)$ & 1 [Reference] \\
\hline & Present & $50(18.9 \%)$ & $1.8(1.2,2.6) 0.004$ \\
\hline \multirow[t]{2}{*}{ Aspartate transaminase (IU/L) } & $<64$ & $181(68.3 \%)$ & 1 [Reference] \\
\hline & $\geq 64$ & $84(31.7 \%)$ & $1.6(1.2,2.2) 0.004$ \\
\hline \multirow[t]{2}{*}{ Serum albumin $(\mathrm{g} / \mathrm{L})$} & $\geq 35$ & $215(80.8 \%)$ & 1 [Reference] \\
\hline & $<35$ & $51(19.2 \%)$ & $1.6(1.1,2.3) 0.027$ \\
\hline
\end{tabular}

Abbrevations: TTP, time to progression; TACE, transarterial chemoembolization; JD, Jie-du.

Table 5: Total hospitalization and admissions costs

\begin{tabular}{|c|c|c|c|c|}
\hline Cost (month) & TACE $+J D(N=75)$ & TACE+Sorafenib $(N=124)$ & TACE $(N=67)$ & $p$ value \\
\hline $\begin{array}{l}\text { Hospitalization costs } \\
\text { (dollar) }\end{array}$ & $1570.60 \pm 748.53$ & $1997.94 \pm 927.39$ & $1830.30 \pm 612.83$ & 0.057 \\
\hline Admission costs (dollar) & $117.47 \pm 17.61$ & 7333.81 & 0 & $<0.001$ \\
\hline
\end{tabular}

Abbrevations: TACE, transarterial chemoembolization; JD, Jie-du.

and diagnose infiltrating HCC. Written informed consent was obtained from all patients at initiation of treatment. Approval of the retrospective analysis by the institutional ethics committee was not required. The study protocol followed appropriate guidelines of the Declaration of Helsinki.

\section{Treatment methods}

TACE was performed by delivering selective transarterial chemotherapy into the vessels feeding the tumor using an emulsion of lipiodol $(5-20 \mathrm{ml})$ and doxorubicin $(30-60 \mathrm{mg})$ followed by embolization 
with absorbable particles (gel foam). The TACE-SOR group was initially administered sorafenib (400 mg) orally twice each day, 3-5 days after the first TACE session, and patients received continuous sorafenib before or after repeated TACE. The dose of sorafenib was reduced according to the presence of toxicity. If grade 3 or 4 hematological, skin or gastrointestinal toxicity, hypertension, or hepatic dysfunction (defined by the National Cancer Institute Common Terminology Criteria for Adverse Events version 3.0) [17] occurred, the dose was adjusted to $400 \mathrm{mg}$ once daily until the adverse events were alleviated or eliminated. If grade 3 or 4 adverse events continued after dose adjustment, sorafenib treatment was halted until the adverse effects were alleviated or disappeared.

The JD preparation comprised the traditional Chinese herbal medicines as follows: root of Actinidia valvata, root of Salvia chinensis, bulb of Cremastra appendiculata, and gizzard membrane of Gallus gallus domesticus (1:1:0.4:0.4), which were extracted using hot water and then lyophilized. In the TACE-JD group, $6 \mathrm{~g}$ (equivalent to $80 \mathrm{~g}$ of raw herbal material) of the JD preparation (Tianjiang Pharmaceutical Factory, Jiangsu, China; Production License No. Su ZzY20010266) was administered twice each day, 30 min after meals.

\section{Follow-up}

Patients were examined as outpatients once every three months after treatment using clinical examination, biochemical analysis, and measurements of serum $\alpha$-fetoprotein. The response of tumors to TACE was evaluated using contrast-enhanced CT or MRI once every 2-3 months after treatment. The modified Response Evaluation Criteria in Solid Tumors (RECIST) definitions were applied to the CT or MRI data to measure tumor response [18], and patients' Child-Pugh classes and ECOG scores were recorded.

\section{Endpoints}

Tumor response to TACE was evaluated 3 months after treatment using contrast-enhanced CT or MRI. The presence of unenhanced tumor areas reflected tissue necrosis. The modified RECIST definitions were applied to CT or MRI data to measure tumor response [18].

\section{Statistical analysis}

Statistical analyses were performed using SPSS 19.0 software (SPSS, Inc., Chicago, IL). Comparisons between two groups were performed using the Student $t$ test for continuous data and the chi-square test for categorical data. OS was calculated using a life-table method and compared with the results of the Mantel-Cox test. Survival curves were generated using the Kaplan-Meier method and compared using the log-rank test. The relative prognostic significance of the variables for predicting OS rates was assessed using multivariate Cox proportional hazards regression analysis. The results are presented as the means \pm standard deviation or median and range. All statistical tests were two-sided and $P<0.05$ indicates a significant difference.

\section{ACKNOWLDGMENTS}

None.

\section{CONFLICTS OF INTEREST}

The authors declare that they have no competing interests.

\section{GRANT SUPPORT}

This work was supported by the National Nature Science Foundation of China (grant number: 81430101), Shanghai Municipal Commission of Health and Family Planning (ZY3-LCPT-2-1004 and ZY3-CCCX-3-7002) and E-institutes of Shanghai Municipal Education Commission (E 03008).

\section{REFERENCES}

1. Ferlay J, Soerjomataram I, Dikshit R, Eser S, Mathers C, Rebelo M, Parkin DM, Forman D, Bray F. Cancer incidence and mortality worldwide: sources, methods and major patterns in GLOBOCAN 2012. Int J Cancer. 2015; 136:E359-86.

2. Siegel RL, Miller KD, Jemal A. Cancer statistics, 2016. CA Cancer J Clin. 2016; 66:7-30.

3. Rampone B, Schiavone B, Confuorto G. Current management of hepatocellular cancer. Curr Oncol Rep. 2010; 12:186-92.

4. Wang W, Zhao Y, Bai W, Han G. Response assessment for HCC patients treated with repeated TACE: the optimal timepoint is still an open issue. J Hepatol. 2015; 63:1530-31.

5. Britten CD, Gomes AS, Wainberg ZA, Elashoff D, Amado R, Xin Y, Busuttil RW, Slamon DJ, Finn RS. Transarterial chemoembolization plus or minus intravenous bevacizumab in the treatment of hepatocellular cancer: a pilot study. BMC Cancer. 2012; 12:16.

6. Qu XD, Chen CS, Wang JH, Yan ZP, Chen JM, Gong GQ, Liu QX, Luo JJ, Liu LX, Liu R, Qian S. The efficacy of TACE combined sorafenib in advanced stages hepatocellullar carcinoma. BMC Cancer. 2012; 12:263.

7. Lin CC, Hsu C, Hsu CH, Hsu WL, Cheng AL, Yang CH. Arsenic trioxide in patients with hepatocellular carcinoma: a phase II trial. Invest New Drugs. 2007; 25:77-84.

8. Lencioni R, Llovet JM, Han G, Tak WY, Yang J, Guglielmi A, Paik SW, Reig M, Kim DY, Chau GY, Luca A, del Arbol LR, Leberre MA, et al. Sorafenib or placebo plus TACE 
with doxorubicin-eluting beads for intermediate stage HCC: The SPACE trial. J Hepatol. 2016; 64:1090-8.

9. Abou-Alfa GK. TACE and sorafenib: a good marriage? J Clin Oncol. 2011; 29:3949-52.

10. Zhao Y, Wang WJ, Guan S, Li HL, Xu RC, Wu JB, Liu JS, Li HP, Bai W, Yin ZX, Fan DM, Zhang ZL, Han GH. Sorafenib combined with transarterial chemoembolization for the treatment of advanced hepatocellular carcinoma: a large-scale multicenter study of 222 patients. Ann Oncol. 2013; 24:1786-92.

11. Qu XD, Chen CS, Wang JH, Yan ZP, Chen JM, Gong GQ, Liu QX, Luo JJ, Liu LX, Liu R, Qian S. The efficacy of TACE combined sorafenib in advanced stages hepatocellullar carcinoma. BMC Cancer. 2012; 12:263.

12. Abdel-Rahman O, Elsayed ZA. Combination trans arterial chemoembolization (TACE) plus sorafenib for the management of unresectable hepatocellular carcinoma: a systematic review of the literature. Dig Dis Sci. 2013; 58:3389-96.

13. Yu Y, Lang Q, Chen Z, Li B, Yu C, Zhu D, Zhai X, Ling C. The efficacy for unresectable hepatocellular carcinoma may be improved by transcatheter arterial chemoembolization in combination with a traditional Chinese herbal medicine formula: a retrospective study. Cancer. 2009; 115:5132-5138.

14. Zhai XF, Chen Z, Li B, Shen F, Fan J, Zhou WP, Yang YK, Xu J, Qin X, Li LQ, Ling CQ. Traditional herbal medicine in preventing recurrence after resection of small hepatocellular carcinoma: a multicenter randomized controlled trial. J Integr Med. 2013; 11:90-100.

15. Meng MB, Cui YL, Guan YS, Ying Z, Zheng MH, Yuan CK, Zhang RM. Traditional Chinese medicine plus transcatheter arterial chemoembolization for unresectable hepatocellular carcinoma. J Altern Complement Med. 2008; 14:1027-42.

16. Chen LY, Zhai XF, Chen Z, Zhu JF, Qian PA, Zhao HT, Ling CQ. Jie-du granule preparation for the treatment of advanced hepatocellular carcinoma: a retrospective cohort study of 177 patients. Oncotarget. 2017; 8:30471-30476. doi: 10.18632/oncotarget.12887.

17. Lencioni R, Llovet JM. Modified RECIST (mRECIST) assessment for hepatocellular carcinoma. Semin Liver Dis. 2010; 30:52-60.

18. National Cancer Institute. Common Terminology Criteria for Adverse Events v.4.0 (CTCAE). Available at: http://ctep. cancer.gov/protocolDevelopment/electronic_applications/ ctc.htm. Accessed June 14, 2011.

19. Llovet JM, Burroughs A, Bruix J. Hepatocellular carcinoma. Lancet. 2003; 362:1907-17.
20. Bruix J, Sherman M, and American Association for the Study of Liver Diseases. Management of hepatocellular carcinoma: an update. Hepatology. 2011; 53:1020-22.

21. Burak KW, Kneteman NM. An evidence-based multidisciplinary approach to the management of hepatocellular carcinoma (HCC): the Alberta HCC algorithm. Canadian journal of gastroenterology. 2010; 24:643-50.

22. Yang M, Yuan JQ, Bai M, Han GH. Transarterial chemoembolization combined with sorafenib for unresectable hepatocellular carcinoma: a systematic review and meta-analysis. Mol Biol Rep. 2014; 41:6575-82.

23. Llovet JM, Bruix J. Systematic review of randomized trials for unresectable hepatocellular carcinoma: chemoembolization improves survival. Hepatology. 2003; $37: 429-42$.

24. Kudo M, Imanaka K, Chida N, Nakachi K, Tak WY, Takayama T, Yoon JH, Hori T, Kumada H, Hayashi N, Kaneko S, Tsubouchi H, Suh DJ, et al. Phase III study of sorafenib after transarterial chemoembolisation in Japanese and Korean patients with unresectable hepatocellular carcinoma. Eur J Cancer. 2011; 47:2117-27.

25. Wu MC. Traditional Chinese medicine in prevention and treatment of liver cancer: function, status and existed problems. [Article in Chinese] Zhong Xi Yi Jie He Xue Bao. 2003; 1:163-64.

26. Ling $C Q$, Yue $X Q$, Ling $C$. Three advantages of using traditional Chinese medicine to prevent and treat tumor. J Integr Med. 2014; 12:331-35.

27. Matsuo K. Frontiers | Progression-free survival and time to progression as surrogate markers of overall survival in patients with advanced gastric cancer: analysis of 36 randomized trials. Adv Med Sci. 2007.

28. Di Maio M, Daniele B, Gallo C, Perrone F. Re: design and endpoints of clinical trials in hepatocellular carcinoma. $\mathrm{J}$ Natl Cancer Inst. 2008; 100:1557-58.

29. Takayasu K, Arii S, Ikai I, Omata M, Okita K, Ichida T, Matsuyama Y, Nakanuma Y, Kojiro M, Makuuchi M, Yamaoka Y, and Liver Cancer Study Group of Japan. Prospective cohort study of transarterial chemoembolization for unresectable hepatocellular carcinoma in 8510 patients. Gastroenterology. 2006; 131:461-69.

30. Ji SK, Cho YK, Ahn YS, Kim MY, Park YO, Kim JK, Kim WT. Multivariate analysis of the predictors of survival for patients with hepatocellular carcinoma undergoing transarterial chemoembolization: focusing on superselective chemoembolization. Korean J Radiol. 2008; 9:534-40. 